\title{
Pneumonia in neonates: can it be managed in the community?
}

\author{
Abhay T Bang, Rani A Bang, V P Morankar, P G Sontakke, J M Solanki
}

\begin{abstract}
Neonatal pneumonia kills about two million children a year worldwide. The World Health Organisation recommends hospitalisation of all cases of pneumonia in the first two months of infancy. In a field trial of community based management of childhood pneumonia in Gadchiroli, India, neonatal pneumonia contributed more than half of the pneumonia deaths. Parents refused referral even when advised therefore community based health workers and traditional birth attendants managed cases of neonatal pneumonia with co-trimoxazole. Case fatality was $15 \%(10 / 65)$ in all cases and $6 \%$ (3/52) in cases without high risk or referral indications. Case fatality in 56 babies aged 30-59 days treated for pneumonia was zero. During the two years of the trial, pneumonia specific mortality rate in the intervention area was $40 \%$ less in the neonates and about $80 \%$ less in the second month and rest of infancy compared with the control area. Pneumonia in the second month of infancy and uncomplicated cases of neonatal pneumonia can be safely and effectively managed in the community using co-trimoxazole.

(Arch Dis Child 1993; 68: 550-556)
\end{abstract}

Pneumonia competes with diarrhoea for the number one position among fatal childhood diseases and is responsible for about four million or $25 \%$ of childhood deaths in developing countries. ${ }^{1}$ In the early 1980 s the World Health Organisation (WHO) initiated a programme for control of acute respiratory infections in children. ${ }^{2}$ Early diagnosis and treatment ('case management') by health workers in the community was proposed as a strategy to reduce childhood deaths from pneumonia. Based on clinical studies, ${ }^{3}$ WHO suggested a simple diagnostic criteria of cough with a respiratory rate of 50 or more; and treatment at home with oral co-trimoxazole or amoxycillin. Children with complications or with signs of very severe disease, such as unconsciousness, convulsions, stridor, or inability to suck or take feeds, were advised referral to hospital. ${ }^{4}$ A few field studies have demonstrated that the case management approach was feasible and effective in reducing pneumonia mortality in children below 5 years of age. ${ }^{56}$ The WHO and UNICEF are now supporting wider applications of this strategy through national acute respiratory infection control programmes in 47 countries. $^{7}$

The acute respiratory infection control programme of the WHO has identified pneumonia in infants below 2 months of age as a problem of the highest research priority. The diagnosis and treatment of pneumonia in this age group is difficult and efficacy of domiciliary management has not been established. The first two months of infancy have been labelled as the 'extended neonatal period' and all cases of pneumonia at this age have been recommended for referral to hospital. ${ }^{8}$ The WHO has also recently suggested severe chest indrawing or a respiratory rate of 60 or more per minute as a new diagnostic criteria of pneumonia in the first two months of infancy. ${ }^{9}$

As no study or experience of community based management of pneumonia in the neonatal period has been published, it is difficult to support or refute WHO recommendations about pneumonia in the first two months.

Systemic bacterial infections in the neonatal period, such as pneumonia, septicaemia, and meningitis are aetiologically and clinically similar and can be divided into two groups: early onset (in first week) and late onset. ${ }^{10}$ The common causative organisms, believed to originate from the birth canal of the mother, were group B streptococci and Escherichia coli as found in the studies in hospitals of developed countries. Combination of ampicillin and an aminoglycoside, gentamicin or kanamycin, is recommended as the treatment. ${ }^{1011}$ Causative organisms in the cases of neonatal septicaemia and pneumonia in the hospital based studies in developing countries were $E$ coli, Klebsiella species, and Staphylococcus aureus. ${ }^{12-15}$

Community based data were not available from rural areas of developing countries where most of the deaths due to neonatal pneumonia took place. After reviewing the reports of 18 hospital based studies on the aetiology of neonatal infections, a WHO group recently concluded that the aetiology of community acquired pneumonia in neonates in developing countries remained unknown. ${ }^{16}$ In the absence of this information it was difficult to choose appropriate antimicrobial agents for community based management of neonatal pneumonia.

We have analysed our experience of a field intervention trial on childhood pneumonia to answer the following research questions: (1) What is the relative importance of pneumonia as the cause of death in different months of infancy in rural areas? (2) Can cases of pneumonia in the first two months of infancy, the so called extended neonatal period, be managed in the community? What is the safety and effectiveness of such management? Which antibiotic should be used for treatment? (3) Is 
extension of the high risk neonatal period to the first two months of infancy justified?

\section{Subjects and methods}

A controlled field trial to test the feasibility and effectiveness of community based case management of pneumonia in children below 5 years of age was conducted in a rural area of a backward district, Gadchiroli, in the central part of India. The area, population characteristics, and methods have been described in detail in an earlier publication. ${ }^{6}$ After a census, all births and childhood deaths from July 1988 to June 1990 were prospectively recorded in the intervention area of 58 villages and an adjacent control area of 44 villages. The control area was similar in every respect, including the health care and the baseline childhood mortality rate, to the intervention area. In the absence of medical certification of deaths, the causes of deaths in children were determined by 'verbal autopsy'. ${ }^{17}$ Pneumonia was considered a cause of death in children having a history of cough and tachypnoea continuously for more than six hours before death. The presence of cough was not an essential criterion in infants up to 2 months of age.

Extensive health education was provided in the intervention area on when to suspect pneumonia in a child and where to seek immediate care. Thirty paramedics belonging to government primary health centres in the intervention area, 25 village health workers of our organisation, SEARCH, and 86 traditional birth attendants in the intervention area were trained to examine sick children and diagnose pneumonia. The presence of cough and a respiratory rate of 50 or more per minute were the criteria of diagnosis of pneumonia in children aged $0-5$ years as advised in the then prevailing guidelines of the WHO. ${ }^{4}$ Respiratory rate was counted when the baby was quiet. If the respiratory rate was raised in neonates, the count was repeated once for confirmation.

Traditional birth attendants were involved because they had a natural and easier access to neonates due to their traditional responsibility of looking after the mother and newborn baby for one to two weeks after delivery. However, because they were illiterate they could not count the respiratory rate. Therefore they were trained to diagnose pneumonia using their visual judgment of tachypnoea. Their judgment of tachypnoea and chest indrawing was cultivated by being shown cases and a video

Breath counter to assist illiterate traditional birth attendants in the diagnosis of pneumonia. Two rows of beads correspond with the age specific respiratory rates for infants below 2 months and 2 to 11 months suggested recently by the WHO. The last bead in each row is red coloured to announce the diagnosis of pneumonia. film on childhood pneumonia that was distributed by WHO. Later on some of them were taught the use of a 'breath counter', a simple device developed by us to diagnose pneumonia in children (figure). ${ }^{18}$ This instrument had a one minute sand timer and an abacus. By turning the instrument upside down, the sand timer was started. Most traditional birth attendants could not count up to 50 but could correctly count up to 10 or 12 . Traditional birth attendants counted the breaths of the sick baby and moved one bead for every 10 breaths counted. If the last bead (sixth, coloured red) in the row for the neonates was moved within one minute, it denoted a respiratory rate of more than 60 per minute, diagnosing the presence of pneumonia.

Management of pneumonia cases included continued breast feeding, syrup co-trimoxazole (sulphamethoxazole $200 \mathrm{mg}$ and trimethoprin $40 \mathrm{mg} / 5 \mathrm{ml}$ ) $2.5 \mathrm{ml}$ twice a day for seven days in children below 6 months and $5 \mathrm{ml}$ twice a day for five days in children of 6 to 59 months. Fever was treated with paracetamol. Cases of pneumonia with stridor, unconsciousness, convulsions, or inability to suck or drink were advised immediate referral. If parents refused to take the child to hospital the health workers were asked to treat the child with co-trimoxazole. The child's age was not a criterion for referral and neonates with pneumonia were also treated in the villages. A case record was completed including clinical signs and symptoms, side effects of treatment, follow up, and outcome of treatment in every case so diagnosed. Field supervisors later visited homes and verified the records. Traditional birth attendants were also trained in safe and hygienic delivery and better care of the neonates; no other intervention targeted to children was introduced.

The population based rates presented here pertain to two years (July 1988 to June 1990) of trial. As the case management service was continued, the cases managed from July 1988 to December 1990 have been included in the analysis. Analysis of causes of death can include more than one cause. Thus when a neonate died of prematurity and pneumonia, the death was included in both the cause specific rates. Such inclusion of multiple causes of death more faithfully represents the multicausal processes leading to death than attributing death to only one underlying cause. ${ }^{17}$ The data were analysed using the statistical software SPSS/PC+. The study protocol of the original field trial was reviewed and approved by a committee of the Indian Council of Medical Research.

It was neither ethical nor feasible to perform lung puncture or blood culture on neonates with pneumonia in the villages. As the organisms causing neonatal pneumonia, especially in the first week, come from the maternal birth canal ${ }^{1011}$ and as no community based information on bacterial flora in the female genital tract was available for rural areas, we have used data from our earlier population based study of gynaecological diseases of rural women in the same area. ${ }^{19}$ In this study swabs were taken 
Table 1 Pneumonia specific mortality in different periods of infancy in control area (Fuly 1988- Fune 1990)

\begin{tabular}{|c|c|c|c|c|c|c|}
\hline & \multicolumn{3}{|c|}{ Neonatal period } & \multicolumn{3}{|c|}{ Postneonatal period } \\
\hline & $0-7$ days & 8-29 days & $0-29$ days & 30-59 days & 2-11 months & $0-11$ months \\
\hline $\begin{array}{l}\text { Pneumonia deaths } \\
\text { Total No of children } \\
\text { Total period of observation (in child years) } \\
\text { Pneumonia mortality rate } / 1000 \text { children } \\
\text { Pneumonia mortality rate } / 1000 \text { child years }\end{array}$ & $\begin{array}{l}31 \\
2098 \\
40 \\
14 \cdot 78 \\
770\end{array}$ & $\begin{array}{l}30 \\
1982 \\
119 \\
14 \cdot 30 \\
251\end{array}$ & $\begin{array}{l}61 \\
2098 \\
158 \\
29 \cdot 08 \\
386\end{array}$ & $\begin{array}{c}9 \\
1923 \\
157 \\
4 \cdot 68 \\
57\end{array}$ & $\begin{array}{l}23 \\
1884 \\
1573 \\
12 \cdot 21 \\
15\end{array}$ & $\begin{array}{l}93 \\
1874^{\star} \\
1873 \\
49 \cdot 63 \\
50\end{array}$ \\
\hline
\end{tabular}

^Mid-year population.

Table 2 Aerobic bacteria grown from the vagina of rural women and their sensitivity to antimicrobial agents ${ }^{*}$

\begin{tabular}{lc} 
Bacteria & Frequency (\%) \\
\hline Escherichia coli & $135(48)$ \\
Staphylococci & \\
$\quad$ Coagulase positive & $35(12 \cdot 3)$ \\
$\quad$ Coagulase negative & $39(13 \cdot 9)$ \\
Klebsiella species & $20(7 \cdot 2)$ \\
Pseudomonas aeruginosa & $11(3 \cdot 9)$ \\
Micrococci & $12(4 \cdot 3)$ \\
Enterococci & $10(3 \cdot 6)$ \\
Streptococci $(\beta$ haemolytic) & $9(3 \cdot 2)$ \\
Proteus & $9(3 \cdot 2)$ \\
Total & 280 \\
& \\
Antimicrobial agent & $N o(\%)$ \\
(concentration) & \\
\hline Penicillin $(10 \mathrm{units})$ & $79(28 \cdot 2)$ \\
Erythromycin $(15 \mu \mathrm{g})$ & $149(53 \cdot 2)$ \\
Tetracycline $(30 \mu \mathrm{g})$ & $227(81 \cdot 1)$ \\
Amoxycillin $(10 \mu \mathrm{g})$ & $245(87 \cdot 5)$ \\
Chloramphenicol $(30 \mu \mathrm{g})$ & $240(85 \cdot 7)$ \\
Ampicillin $(10 \mu \mathrm{g})$ & $243(86 \cdot 8)$ \\
Streptomycin $(10 \mu \mathrm{g})$ & $258(92 \cdot 1)$ \\
Co-trimoxazole $(25 \mu \mathrm{g})$ & $263(93 \cdot 9)$ \\
Gentamicin $(10 \mu \mathrm{g})$ & $266(95 \cdot 0)$ \\
Gentamicin $+\mathrm{co}-\mathrm{trimoxazole}$ & $280(100)$ \\
&
\end{tabular}

$\star$ All bacteria combined.

from the vagina in 546 symptomatic as well as asymptomatic women from the villages. Culture for anaerobic bacteria, gonococci, or chlamydia could not be performed and the culture for aerobic bacteria yielded 280 positive results. This information was an indirect indicator of the bacteria possibly causing early onset neonatal pneumonia in the area and their antimicrobial sensitivity.

\section{Results}

Pneumonia mortality rates in different periods of infancy in the control area are presented in table 1. Mortality rates are presented first as per thousand children. As the periods of observation are not uniform in various age groups, the rates are also presented as per 1000 child years of observation. The pneumonia mortality in $0-29$ days contributed $66 \%$
(61/93) of pneumonia mortality in infancy and $54 \%(61 / 113)$ in the children under 5 years.

The aerobic organisms grown from the vaginas of women in the community and their sensitivity to the antimicrobial agents is presented in table 2 .

Table 3 presents details of diagnostic clinical features in 65 cases of pneumonia in the first month and 56 cases in the second month of infancy, treated by different types of health workers. The agreement of the health workers' diagnoses with the revised WHO criteria (1990) is presented in table 4. Referral indications were present in nine neonates between 0-29 days of age (convulsions in two, unconsciousness in five, inability to take feeds in five, and stridor in one) and in two infants between 30-59 days of age (inability to take feeds in both). Despite the advice of health workers, parents of 10 out of 11 babies needing referral refused to take them to a doctor or hospital and hence health workers treated these cases. One referred and one unreferred neonate were taken to a doctor and co-trimoxazole discontinued; both died. These two deaths have been included as case fatalities with the respective health workers in the analysis.

The outcome of case management by different types of workers expressed as case fatality ratio was as follows: in the group aged 0-29 days, village health workers managed 25 cases, out of which two died $(8 \%)$; paramedics managed seven cases, out of which one died $(14 \%)$; and traditional birth attendants managed 33 cases, out of which seven died (21\%). The difference in case fatality was not statistically significant. Overall case fatality in the treated neonates was 15\% (10/65). Fifty six cases of pneumonia in the age group 30-59 days were managed with no deaths (village health workers, 34 cases; paramedics, three cases; and traditional birth attendants, 19 cases). The outcome of community based management in various risk groups in $0-29$ days old children is presented in table 5 .

Table 3 Clinical features in cases of pneumonia managed by community based workers (fuly 1988-December 1990)

\begin{tabular}{|c|c|c|c|c|c|c|c|c|c|c|}
\hline \multirow[b]{3}{*}{ Type of worker } & \multicolumn{5}{|c|}{ Age 0-29 days } & \multicolumn{5}{|c|}{ Age 30-59 days } \\
\hline & \multirow[b]{2}{*}{$\begin{array}{l}\text { No of } \\
\text { cases }\end{array}$} & \multicolumn{2}{|c|}{ Respiratory rate } & \multicolumn{2}{|c|}{$\begin{array}{l}\text { Severe chest } \\
\text { Indrawing }\end{array}$} & \multirow[b]{2}{*}{$\begin{array}{l}\text { No of } \\
\text { cases }\end{array}$} & \multicolumn{2}{|c|}{ Respiratory rate } & \multicolumn{2}{|c|}{$\begin{array}{l}\text { Severe chest } \\
\text { Indrawing }\end{array}$} \\
\hline & & Rate & $\begin{array}{l}\text { No of } \\
\text { cases }\end{array}$ & Present & Absent & & Rate & $\begin{array}{l}\text { No of } \\
\text { cases }\end{array}$ & Present & - Absent \\
\hline Village health workers & 25 & $\begin{aligned} & 50-59 \\
> & 60\end{aligned}$ & $\begin{array}{r}3 \\
22\end{array}$ & $1^{1^{\star}}$ & $\underset{11^{\star}}{2}$ & 34 & $\begin{aligned} & 50-59 \\
> & 60\end{aligned}$ & $\begin{array}{l}11 \\
23\end{array}$ & $\begin{array}{l}1^{\star} \\
7^{\star}\end{array}$ & $\begin{array}{l}10 \\
16^{\star}\end{array}$ \\
\hline Paramedics & 7 & $\begin{array}{l}50-59 \\
>60\end{array}$ & $\begin{array}{r}22 \\
2 \\
5\end{array}$ & $\begin{array}{l}2^{\star} \\
4^{\star}\end{array}$ & $\overline{1}^{\star}$ & 3 & $50-59$ & 3 & $1^{\star}$ & 2 \\
\hline Traditional birth attendants & 33 & Not counted & & $13^{\star}$ & 20 & 19 & Not known & & $7^{\star}$ & 12 \\
\hline Total & 65 & & 65 & 31 & 34 & 56 & & 56 & 16 & 40 \\
\hline
\end{tabular}

${ }^{\star}$ Cases fulfilling revised (1990) WHO criteria of pneumonia. ${ }^{9}$ 
Table 4 Diagnosis by revised WHO criteria in cases of pneumonia managed by community based workers (fuly 1988-December 1990). Results are number (\%)

\begin{tabular}{|c|c|c|}
\hline & 0-29 days & 30-59 days \\
\hline $\begin{array}{l}\text { Cases fulfilling WHO criteria* } \\
\text { Cases not fulfilling WHO criteria }\end{array}$ & $\begin{array}{c}43(66) \\
2(3)\end{array}$ & $\begin{array}{l}32(57) \\
12(21 \cdot 5)\end{array}$ \\
\hline $\begin{array}{l}\text { Information inadequate to judge } \\
\text { by WHO criteriat }\end{array}$ & $20(31)$ & $12(21 \cdot 5)$ \\
\hline Total & $65(100)$ & $56(100)$ \\
\hline
\end{tabular}

* Revised WHO criteria (1990) of pneumonia in infants ${ }^{9}:$ respiratory rate $>60$ per minute or presence of severe chest indrawing or both.

†Respiratory rate not counted, no indrawing of chest but traditional birth attendant judged baby to be tachypnoeic.

Impact of interventions on the pneumonia specific mortality rate in different months of infancy in the intervention and the control area are presented in table 6 . In the intervention area the pneumonia mortality in neonatal period constituted $84 \%$ (54/64) of the pneumonia mortality in infants and $67.5 \%(54 / 80)$ in children below 5 years. The impact of interventions on acute respiratory infections on the total mortality in different months of infancy is presented in table 7 .

\section{Discussion}

Neonatal pneumonia contributed more than half of the pneumonia deaths in children below 5 years of age. Thus it deserved the highest priority in the acute respiratory infection control programme. In the intervention area, parents refused to take seriously ill neonates to hospital even when referred. Domiciliary management by the community based workers using co-trimoxazole syrup resulted in zero case fatality in the second month of infancy. In the first month, case fatality was $15 \%$ in all cases and $6 \%$ in cases without referral indication or high risk factor. Traditional birth attendants provided half of the case management of pneumonia in the neonatal period. The case management led to a $40 \%$ reduction in the pneumonia specific mortality rate in the neonatal period, $78 \%$ in the second month, and $80 \%$ for the rest of infancy. Study of vaginal flora in the community suggested that co-trimoxazole could be a good choice to cover the aerobic bacteria, however, a combination of gentamicin and co-trimoxazole should produce the best results.

There was definite evidence that community based management of neonatal pneumonia was necessary, feasible, and effective. Pneumonia in the second month of infancy was like that of remaining postneonatal infancy and could be safely and effectively managed by community based health workers. It should not be combined with the first month of infancy and need not be an indication of referral by itself. WHO guidelines need to be reconsidered in this light.

Earlier studies have found good correlation between the pathogenic bacteria colonising neonates and bacteria in the maternal vagina. ${ }^{1320}$ Moreover, the bacteria found in the maternal vagina in this study were very similar to the bacteria grown by blood culture from neonates with sepsis in earlier hospital based studies. Hence bacterial flora in the maternal vagina may be accepted as a surro-

Table 5 Outcome of community based management of neonatal pneumonia in different risk groups (Fuly 1988-December 1990)

\begin{tabular}{lcccc}
\hline Description & Dead & Survived & Total & $\begin{array}{c}\% \text { Case fatility } \\
(95 \% \text { CI })\end{array}$ \\
\hline 0-7 days (all cases) & 5 & 16 & 21 & $24(6$ to 41$)$ \\
8-29 days (all cases) & 5 & 39 & 44 & $11(2$ to 20) \\
0-29 days (all cases) & 10 & 55 & 65 & $15(6$ to 24$)$ \\
Cases with referral indications & 3 & 6 & 9 & $33(2$ to 64$)$ \\
Cases without referral indications & 7 & 49 & 56 & $13(4$ to 22) \\
Cases without referral indications or without risk factors of death† & 3 & 49 & 52 & $6(0$ to 12$)$ \\
\hline
\end{tabular}

^Referral indications: see result section in text.

tRisk factors were associated with seven deaths: prematurity $(n=4)$, small sized full term $(n=2)$, birth injury $(n=4)$, failure of feeding $(n=1)$. The presence of these risk factors in those who survived is not known.

Table 6 Impact of community based management on pneumonia specific mortality rate in different months of infancy (Fuly 1988-Fune 1990)

\begin{tabular}{|c|c|c|c|c|c|c|c|}
\hline \multirow[b]{2}{*}{ Age group } & \multicolumn{3}{|l|}{ Control area } & \multicolumn{3}{|c|}{ Intervention area } & \multirow[b]{2}{*}{$\begin{array}{l}\% \\
\text { Reduction }\end{array}$} \\
\hline & $\begin{array}{l}\text { No of } \\
\text { pneumonia } \\
\text { deaths }\end{array}$ & $\begin{array}{l}\text { Total } \\
\text { No of } \\
\text { children }\end{array}$ & $\begin{array}{l}\text { Rate per } 1000 \\
\text { children }(95 \% \text { CI })\end{array}$ & $\begin{array}{l}\text { No of } \\
\text { pneumonia } \\
\text { deaths }\end{array}$ & $\begin{array}{l}\text { Total } \\
\text { No of } \\
\text { children }\end{array}$ & $\begin{array}{l}\text { Rate per } 1000 \\
\text { children }(95 \% \text { CI })\end{array}$ & \\
\hline $\begin{array}{l}0-29 \text { days } \\
30-59 \text { days } \\
2-11 \text { months } \\
0-11 \text { months }\end{array}$ & $\begin{array}{r}61 \\
9 \\
23 \\
93\end{array}$ & $\begin{array}{l}2098 \\
1923 \\
1884 \\
2098\end{array}$ & $\begin{array}{c}29 \cdot 1(21 \cdot 9 \text { to } 36 \cdot 3) \\
4 \cdot 7(1 \cdot 6 \text { to } 7 \cdot 7) \\
12 \cdot 2(7 \cdot 3 \text { to } 17 \cdot 2) \\
44 \cdot 3(35 \cdot 5 \text { to } 53 \cdot 1)\end{array}$ & $\begin{array}{r}54 \\
3 \\
7 \\
64\end{array}$ & $\begin{array}{l}3100 \\
2904 \\
2856 \\
3100\end{array}$ & $\begin{array}{c}17 \cdot 4(12 \cdot 8 \text { to } 22 \cdot 0) \\
1 \cdot 0(0 \text { to } 2 \cdot 2) \\
2 \cdot 5(0 \cdot 6 \text { to } 4 \cdot 3) \\
20 \cdot 1(15 \cdot 6 \text { to } 25 \cdot 7)\end{array}$ & $\begin{array}{l}40 \\
78 \\
80 \\
55\end{array}$ \\
\hline
\end{tabular}

Table 7 Impact of interventions for acute respiratory infection on total mortality in different months of infancy (Fuly 1988-Fune 1990)

\begin{tabular}{|c|c|c|c|c|c|c|c|}
\hline \multirow[b]{2}{*}{ Age group } & \multicolumn{3}{|c|}{ Control area } & \multicolumn{3}{|c|}{ Intervention area } & \multirow[b]{2}{*}{$\begin{array}{l}\% \\
\text { Reduction }\end{array}$} \\
\hline & $\begin{array}{l}\text { No of } \\
\text { total } \\
\text { deaths }\end{array}$ & $\begin{array}{l}\text { Total } \\
\text { No of } \\
\text { children }\end{array}$ & $\begin{array}{l}\text { Rate per } 1000 \\
\text { children }(95 \% \text { CI })\end{array}$ & $\begin{array}{l}\text { No of } \\
\text { total } \\
\text { deaths }\end{array}$ & $\begin{array}{l}\text { Total } \\
\text { No of } \\
\text { children }\end{array}$ & $\begin{array}{l}\text { Rate per } 1000 \\
\text { children }(95 \% \mathrm{CI})\end{array}$ & \\
\hline $\begin{array}{l}0-29 \text { days } \\
30-59 \text { days } \\
2-11 \text { months } \\
0-11 \text { months }\end{array}$ & $\begin{array}{r}176 \\
16 \\
43 \\
235\end{array}$ & $\begin{array}{l}2098 \\
1923 \\
1884 \\
2098\end{array}$ & $\begin{array}{c}83 \cdot 9(72 \cdot 0 \text { to } 95 \cdot 8) \\
8 \cdot 3(4 \cdot 3 \text { to } 12 \cdot 4) \\
22 \cdot 8(16 \cdot 1 \text { to } 29 \cdot 6) \\
112 \cdot 0(98 \cdot 5 \text { to } 125 \cdot 5)\end{array}$ & $\begin{array}{r}197 \\
11 \\
53 \\
261\end{array}$ & $\begin{array}{l}3100 \\
2904 \\
2856 \\
3100\end{array}$ & $\begin{array}{c}63 \cdot 6(55 \cdot 0 \text { to } 72 \cdot 1) \\
3 \cdot 8(1 \cdot 6 \text { to } 6 \cdot 0) \\
18 \cdot 6(13 \cdot 6 \text { to } 23 \cdot 5) \\
84 \cdot 2(74 \cdot 4 \text { to } 94 \cdot 0)\end{array}$ & $\begin{array}{l}24 \\
57 \\
19 \\
25\end{array}$ \\
\hline
\end{tabular}


gate indicator of organisms causing neonatal pneumonia and sepsis, especially the highly fatal early onset disease. The data presented in table 2 provide a glimpse of the vaginal flora in the community where most of the cases of neonatal pneumonia occur. It showed that aminoglycosides (gentamicin or streptomycin) or co-trimoxazole were the most appropriate antibiotics. The therapeutic results to co-trimoxazole, as observed in this study, substantiate the in vitro findings. Combining an aminoglycoside, gentamicin, with oral co-trimoxazole may produce the best results as the sensitivity to this combination was $100 \%$. The use of penicillin as reported in a study from Haryana, India, ${ }^{21}$ would have been wrong.

In the natural setting of the control area (table 1), 29 neonates per 1000 live births died of pneumonia in the first month of life $(95 \%$ confidence interval (CI) 21.9 to 36.3 ) compared with 4.68 in the second month (CI 1.6 to $7 \cdot 7$ ). When converted to a uniform time scale of pneumonia mortality rate/ 1000 child years of observation, the mortality rate in the neonatal period (0-29 days) was about 25 times higher than in 2-11 months of infancy, establishing the importance of pneumonia in the first month of life. Pneumonia mortality rate in the second month was about seven times less compared with the first month. The two periods were distinctly different.

The overall case fatality in the 65 cases of neonatal pneumonia managed in the community was $15 \%$ (95\% CI $6 \%$ to $24 \%$ ) (table 5). This was very high compared with less than $1 \%$ case fatality in all childhood pneumonia cases managed by the same workers in this trial $^{6}$ or zero fatality in the 56 treated cases of pneumonia in the second month. The neonates were obviously a high risk group and their management was difficult. However a $15 \%$ case fatality compared favourably with the $22 \%$ to $55 \%$ fatality in cases of neonatal pneumonia managed in Indian hospitals. ${ }^{22-24}$ The lower fatality in this study compared with the hospital studies could reflect the differences in diagnostic criteria and seriousness of cases managed in the community compared with the hospital. This may reflect the advantage of community based management because the pneumonia was diagnosed and treated at the early stage. There are no published data on fatality in cases of neonatal pneumonia acquired and managed in the community for comparing with our experience.

As shown in table 5, the case fatality was higher $(24 \%)$ in the first week (many of these could be cases of hyaline membrane disease or aspiration), and in cases with referral indications $(33 \%)$. The data on the presence of risk factors such as birth injury, prematurity, small size, or failure of feeding were available only for dead children. If such deaths with risk factors and children with referral indications were excluded from the analysis (13/65), the case fatality in the remaining 52 cases of uncomplicated neonatal pneumonia was $6 \%$. Thus community based case management in neonates with pneumonia without referral indication or a high risk factor was effective. Parents refused referral in 10 out of 11 indicated cases and health workers had no alternative but to manage the sick neonates at home.

The case fatality ratio was least $(8 \%)$ with the village health workers and highest $(21 \%)$ in the cases managed by traditional birth attendants, though the difference was not statistically significant. Traditional birth attendants managed about $50 \%$ of the cases in the neonatal period, underscoring their strategic position in access to the neonates. Higher case fatality ratio in cases managed by traditional birth attendants could be partly because of their illiteracy and therefore lower potential for learning, but it was compensated for by their traditional access to neonates that was often denied to other workers. In any case, the case fatality with the traditional birth attendants $(21 \%)$ was less than 22 to $55 \%$ as reported from the hospitals. ${ }^{22-24}$

The zero case fatality in the 56 cases of pneumonia in the second month of infancy suggested that these cases need not necessarily be referred to hospital as currently recommended by the WHO.

Impact: the interventions for the two years were associated with $40 \%$ reduction in the pneumonia mortality rate in babies of 0-29 days compared with the control area. The two areas were similar at baseline. ${ }^{625}$ Training of traditional birth attendants in safe delivery and neonatal care also contributed to the reduction in neonatal mortality by other causes such as birth asphyxia and prematurity ${ }^{6}$ but did not contribute directly to reduction in pneumonia specific mortality. The reduction in pneumonia mortality in the neonatal period was only about half of the reduction in the second month or between 2-11 months of infancy $(40 \%$ as against $78 \%$ or $80 \%$ ) again underscoring difficulties in overcoming pneumonia mortality in the neonatal period. The $40 \%$ reduction in the neonatal period contributed greater absolute reduction in the infant mortality than $78 \%$ reduction in the second month because the rate was very high in the neonatal period. The $78 \%$ reduction in the second month and $80 \%$ between $2-11$ months again showed that pneumonia in the second month behaved like the rest of the infancy and not like the neonatal period.

Despite intervention, neonatal pneumonia emerged as the most prominent problem contributing $67.5 \%$ of the pneumonia deaths in childhood in the intervention area as against $54 \%$ in the control area. This was because pneumonia mortality in the neonatal period declined by $40 \%$ compared with an $80 \%$ decline in the postneonatal age. Hence the proportion of deaths caused by neonatal pneumonia in the residual pneumonia deaths increased, though the absolute number of deaths due to pneumonia decreased. Thus, as the acute respiratory infection control programme becomes effective, relative importance of neonatal pneumonia will increase.

The reduction in pneumonia mortality was accompanied by a reduction in the total neonatal and infant mortality (table 7). Neonatal mortality rate in the intervention area declined 
from 83.9 to $63 \cdot 6 / 1000$. Reduction in pneumonia specific mortality could explain $57 \%$ of this reduction in neonatal mortality. The remaining $43 \%$ was probably due to the training and supervision of traditional birth attendants resulting in an improved quality of neonatal care in the intervention area.

The reasons for successful results were:

- Extensive health education of the adult population.

- Good community acceptance.

- Involvement of traditional birth attendants in case management.

- Training of traditional birth attendants using video film and the breath counter.

- Choice of co-trimoxazole, validated by the study of vaginal flora. No side effects of co-trimoxazole were recorded despite active inquiry in all treated cases.

- Early diagnosis and treatment at home.

What were the sources of possible artefact? There could have been some diagnostic errors by health workers. In this study cough with a respiratory rate of 50 or more was considered diagnostic of pneumonia by the then prevailing WHO guidelines; subsequently the WHO revised its criteria. Yet, as shown in table 4, $66 \%$ of the managed cases in the 0-29 day period met new WHO criteria, 3\% did not, and in $31 \%$ the respiratory rate was not known but traditional birth attendants judged the cases as pneumonia. A similar pattern was seen in cases in the second month. In another study we found that traditional birth attendants' visual judgment of tachypnoea matched in 60 to $90 \%$ of cases (depending upon the range of the respiratory rate) with the diagnosis of the new WHO criteria. ${ }^{18}$ Traditional birth attendants and other workers were trained by being shown video films from the WHO to recognise chest indrawing. So this judgment too should match. Thus most of the diagnosed cases were true cases of pneumonia by the WHO criteria. But the WHO criteria themselves may have picked up some false positive cases thereby lowering the case fatality. ${ }^{26}$ However that could not have lowered pneumonia mortality rate or the neonatal mortality rate at the population level in the intervention area.

Some excessive diagnosis of pneumonia as the cause of death, especially in the early neonatal period, was possible because the criterion of tachypnoea for more than six hours before death would also include deaths due to hyaline membrane disease or aspiration. This may be partly responsible for the high $(24 \%)$ case fatality in the 0-7 day age group. The verbal autopsy method also was less than perfect. But its use has been validated by many studies. ${ }^{6} 17$ Moreover as the same definition of pneumonia as cause of death and the same method of verbal autopsy were employed in the intervention and the control area, the observed reduction was true and not an artefact.

There were several problems that had to be faced in the management of neonatal pneumonia.

(1) Near total $(10 / 11)$ refusal by parents to take the neonate with indications of referral to hospital. The hospitals are too far and, traditionally, a neonate even if sick is not taken outside the home. Hence the management for neonatal pneumonia must be improved and provided in the community.

(2) A substantial number of neonates with pneumonia in the intervention area were still unattended, mostly because parents did not seek care. We do not have an estimate of the incidence of neonatal pneumonia, hence we cannot estimate the proportion of unattended neonatal pneumonia.

(3) Co-trimoxazole was less than an ideal choice of antibiotic because not all organisms were sensitive and because the oral route of administration may not be reliable in the neonates. Part of the case fatality could be due to this. We believe that the addition of gentamicin should overcome these deficiencies and should further reduce fatality due to pneumonia as well as sepsis in the neonatal period.

(4) Pneumonia in the first week or in babies with risk factors such as prematurity, birth injury, and small size was associated with high case fatality despite treatment and they need hospitalisation.

(5) Illiteracy of the traditional birth attendants limited their learning. To improve the traditional birth attendants' diagnosis of pneumonia, we have developed a simple device, the 'breath counter'. Using this device, traditional birth attendants could make a correct diagnosis in $82 \%$ of cases with a borderline respiratory rate (difficult for diagnosis). ${ }^{18}$

The significance of the findings of this study are threefold:

(1) It presents the first definite evidence that pneumonia in the neonatal period can be managed in the community. Approximately half of the total pneumonia deaths or about 2 million childhood deaths take place due to neonatal pneumonia. This approach can prevent most of these deaths.

(2) It refutes the WHO's recommendation that all cases of pneumonia in the second month of infancy should be referred to hospital. These cases can be safely and effectively managed in the community.

(3) Community based management of pneumonia in the first two months will cut down unnecessary referral, reducing the workload in hospitals and cost and anxiety to the parents. It will also enhance credibility of community based workers.

It is fit to end this discussion with some anecdotal experiences. Maruti, our village health worker from a village called Wasa, successfully managed a case of neonatal pneumonia that a doctor practising in the rural area had earlier refused to treat because of the high risk. Traditional birth attendants have successfully treated neonatal and childhood pneumonia. Yashodabai, an illiterate traditional birth attendant, successfully treated a case of neonatal pneumonia that a private nursing home (without a paediatrician) in the town could not manage. The health workers' reputation spreads by word of mouth and many rural medical practitioners now refer cases of childhood pneumonia to our village health workers 
and traditional birth attendants in the intervention area. Is this not one more step towards 'health by the people'?

The study could not have been completed without the cooperative people of Gadchiroli; the field supervisors, R Wargantiwar, $P$ Kelzarkar, A Dudhbade, and D Jengthe; 43 Arogya Doots, and 86 traditional birth attendants. Mr D M Deotale typed the manuscript. SEARCH was supported by the Indian Council of Medical Research, the Ford Foundation, and Oxfam during the period of study.

1 Leoswki J. Mortality from acute respiratory infections in children under five years of age: global estimates. World Health Stat $Q 1986 ; 39:$ 138-44.

2 World Health Organisation. Guidelines for research on acute respiratory infections: memorandum from a WHO meeting. Bull WHO 1982; 60: 521-33.

3 Shann F, Hart K, Thomas D. Acute lower respiratory tract infection in children: possible criteria for selection of patients for antibiotic therapy and hospital admissions. Bull WHO 1984; 62: 749-53.

4 World Health Organisation. Respiratory infections in children management in small hospital: a manual for doctors. Geneva: management in

5 World Health Organisation. Case management of acute respiratory infections in children: intervention studies. Geneva: WHO, 1988. (WHO/ARI/88.2.)

6 Bang AT, Band RA, Tale O, et al. Reduction in pneumonia mortality and total childhood mortality by means of community based intervention trial in Gadchiroli, India. Lancet 1990; 336: 201-6.

7 World Health Organisation. Programme for the control of acute respiratory infections. Report of sixth meeting of the technical advisory group, Geneva, 11-15 March 1991. Geneva: WHO, 1991. (WHO/ARI/91.18.)

8 World Health Organisation. Programme of acute respiratory infections. Report of fourth meeting of technical advisory infections. Report of fourth meeting of technical advisory group $6-10$ March

9 World Health Organisation. Acute respiratory infections in children: case management in small hospitals in developing countries. Geneva: WHO, 1990. (WHO/ARI/90.5.)

10 Avery ME, Taeusch H, eds. Bacterial infections in the newborn. Schaffer's diseases of newborn. Philadelphia: WB Saunders, 1984: 729-31.

11 Behraman RE, Vaughan VC, eds. Nelson textbook of pediatrics. 13th Ed. Philadelphia: WB Saunders, 1987: 425-8.
12 Bhalla M, Bhalla JN. Clinical and bacteriological profile of the neonatal infections. Archives of Child Health 1984; 26: 13-7.

13 Kishore K, Deorarai AK, Meharban Singh, Bhujwala RA. Early onset neonatal sepsis - vertical transmission from maternal genital tract. Indian Pediatr 1987; 24: 45-8.

14 Namdeo UK, Singh HP, Rajput VJ, Shrivastava KK, Namdeo $S$. Bacteriologic profile of neonatal septicaemia. Indian Pediatr 1987; 24: 53-6.

15 Bhatia BD, Chug S, Narang P, et al. Bacterial flora of new born at birth and 72 hours of age. Indian Pediatr 1988; 25: 1058-65.

16 World Health Organisation. Clinical signs and etiological agents of pneumonia, sepsis and meningitis in young agents of pneumonia, sepsis and meningitis in young
infants. Report of meeting, Geneva 21-24 November infants. Report of meeting, Geneva 21-24 November infections. Geneva: WHO, 1990. (WHO/ARI/90.14.)

17 Gray RH, Smith G, Barss P. The use of verbal autopsy method to determine selected causes of death in children. (Occasional Paper No 10.) Baltimore: Institute for International Programmes, The Johns Hopkins University, School of Hygiene and Public Health, 1990.

18 Bang AT, Bang RA. Breath counter for diagnosis of childhood pneumonia. Lancet 1991; 338: 116.

19 Bang RA, Bang AT, Baitule M, et al. High prevalence of gynaecological diseases in rural Indian women. Lancet 1989; i: 85-8.

20 Remington JS, Klein JO. Infectious diseases of the fetus and newborn infant. Philadelphia: WB Saunders, 1990: 602-9.

21 Datta N, Kumar V, Kumar L, Singhi S. Application of casemanagement to the control of acute lower respiratory infections in low birth weight infants: a feasibility study. infections in low birth weigh

22 Thomas S, Verma IC, Singh M, Menon PSN. Spectrum of respiratory distress syndrome in new born in north India: a prospective study. Indian 7 Pediatr 1981; 48: $61-5$.

23 Khatua SP, Gangwal A, Basu P, Roy Palodhi PK. The incidence and etiology of respiratory distress in new born. Indian Pediatr 1979; 16: 1121-6.

24 Misra PK. Respiratory distress in new born: a prospective study. Indian Pediatr 1987; 24: 77-9.

25 Bang AT, Bang RA. Community-based approach to pneumonia. Lancet 1990; 336: 1129-30.

26 Cherian T, John TJ, Simoes E, Steinhoff MC, John M. Evaluation of simple clinical signs for the diagnosis of acute lower respiratory tract infection. Lancet 1988; ii: 125-8. 